\title{
Epidemiological, clinical and therapeutical aspects of road traffic accident in 1034 children admitted at Niamey National Hospital - Niger
}

\author{
Chaibou MS ${ }^{1 *}$, Daddy H ${ }^{1}$, James Didier L ${ }^{2}$, Ayouba I ${ }^{1}$, Gagara $\mathrm{M}^{1}$, Garba I ${ }^{2}$, Sanoussi $\mathrm{S}^{2}$, Abarchi $\mathrm{H}^{2}$ and Zoumenou $\mathrm{E}^{3}$ \\ ${ }^{1}$ Department of Anesthesiology, Niamey National Hospital - Niger \\ ${ }^{2}$ Department of Surgery, Niamey National Hospital \\ ${ }^{3}$ School of Medicine - Cotonou, Bénin
}

\section{Introduction}

Road traffic accident is a great public health problem in the world. According to the WHO, road traffic accidents worldwide account for 1.2 million deaths and 50 million injuries per year. Africa ranks first in terms of victims, with 28 deaths per 100,000 habitants. According to a WHO study, between 1990 and 2020: Traffic accidents will become the sixth leading cause of death worldwide and will also become the third leading cause of disability. They will become the second leading cause of loss of life years adjusts on disability in low- and middle-income countries [1-3]. The aim of this study was to study the epidemiological, clinical and therapeutical aspects of trauma related to road accidents in children admitted to the emergency unit of Niamey National Hospital.

\section{Methods}

The prospective study was conducted in the emergency unit of Niamey National Hospital (NNH). Data was gathered from January to December 2013. Were included all children between 0 to 15 years admitted to the surgical emergency unit for injuries related to road accidents, were excluded victims who died in pre-hospital. The following variables were analyzed: age, sex, provenance, level of education, type and time of accident, time of admission, lesions, treatment, duration stay in emergency, and expenses. Data were analyzed with Epi-Info 6TM (Centers for Disease Control and Prevention, Atlanta, GA.

\section{Results}

The sample included 1034 patients, aged 0 to 15 years out of 2546 victims of traffic accidents admitted to the $\mathrm{NNH}$ surgical emergencies ( $40.61 \%$ of the victims). The locations of the accident were the urban community of Niamey in $95.79 \%$; $1.15 \%$ came from the region of Tillabéry which borders Niamey. The average age was 8 \pm 3 years with extremes ranging from 12 weeks to 15 years. (Figure 1) Males represented $71 \%$, with a male to female ratio of $2.44: 1$. This male predominance is found in all age groups. $54.15 \%$ of our patients were schoolboys. Accidents occurred most often between 2: AM to 6: $\mathrm{PM}$ in $42.64 \%$ of the cases. The mechanism of the accident was carpedestrian in $34.42 \%$, motor-pedestrian in $33.84 \%$ (Table 1) Prehospital transportation was provided by a private vehicle in $40.6 \%$ of the cases, taxi in $38.20 \%$, by firefighters and paramedics in respectively $13.60 \%$ and $4.70 \%$. The transport was done by the SAMU in $2.90 \%$ of our patients. Admission was in less than one hour in $89.16 \%$ of patients. Closed trauma represented $79.10 \%$, open trauma $19.90 \%$ and associations $1 \%$. Cerebral injury was the most common lesion with $33.94 \%$ followed by limb trauma seen in $18.37 \%$ of patients. (Table 2 )

Table 1. Distribution of patients by type of accident.

\begin{tabular}{|c|c|c|}
\hline Accident & Effective & Percentage \% \\
\hline Auto-pedestrian & 356 & 34,42 \\
\hline Motorbike - pedestrian & 350 & 33,84 \\
\hline Auto - motorbike & 135 & 13,05 \\
\hline Motorbike fall & 55 & 5,31 \\
\hline Motorbikes collision & 45 & 4,35 \\
\hline Bicycle & 26 & 2,51 \\
\hline Auto reversed & 22 & 2,12 \\
\hline Auto collision & 14 & 1,35 \\
\hline Autres & 31 & 2,99 \\
\hline TOTAL & $\mathbf{1 0 3 4}$ & $\mathbf{1 0 0} \%$ \\
\hline
\end{tabular}

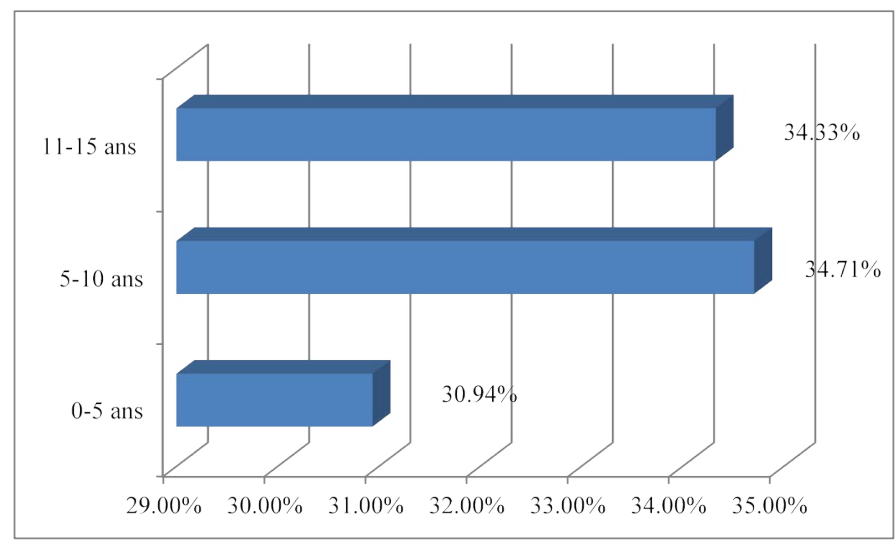

Figure 1. Distribution of patients by age.

Correspondence to: Maman Sani Chaibou, Department of Anesthesiology Niamey National Hospital, BP 10337 Niamey - Niger; Tel: 0022794777766; E-mail: chaibou_msani@yahoo.fr

Key words: Road traffic accident, emergency unit, therapeutical aspects, surgical emergency, accident

Received: June 10, 2017; Accepted: July 03, 2017; Published: July 06, 2017 
Table 2. Distribution of patients according to the seat of the lesion

\begin{tabular}{|c|c|c|}
\hline Trauma & Effective & Percentage $\%$ \\
\hline Skull & $\mathbf{3 5 1}$ & $\mathbf{3 3 , 9 4}$ \\
\hline Limbs & 190 & 18,37 \\
\hline Abdomen & 57 & 5,51 \\
\hline Basin & 54 & 5,22 \\
\hline Rachis & 50 & 4,83 \\
\hline Thorax & 45 & 4,35 \\
\hline Associations & 287 & 27,75 \\
\hline Total & $\mathbf{1 0 3 4}$ & $\mathbf{1 0 0} \%$ \\
\hline
\end{tabular}

In our study, $45.97 \%$ of patients had received analgesics alone or in combination. The most common analgesic used was paracetamol alone $(53.03 \%)$ or associated to codeine (33.85\%). $35.62 \%$ of patients received antibiotic, and $2.42 \%$ of patients were sedated. Blood transfusion involved $0.31 \%$ of patients. Surgical treatment was a simple suture in $79.87 \%$ of cases, a plastered Immobilization in $47.67 \%$. The osteosynthesis involved $5.48 \%$ of patients, laparotomy $4.87 \%$, thoracic drainage $3.04 \%$ and limb amputation $1.40 \% .50 .8 \%$ of patients had stayed between 1 and 8 hours in the emergency care unit, $84.20 \%$ of the patients had a hospital stay of less than 24 hours. Eight cases of death $(0.77 \%)$ were recorded. The cost of care ranged between 15 and 60 US \$ for $42.77 \%$ of patients with an average cost of 50 US \$, keeping in mind that health care is free for children below 5 years of age in Niger.

\section{Conclusion}

Trauma related to road traffic accidents in children is common in surgical emergency department. The pedestrian on the school path is the most concerned and the trauma affects mostly the skull. Even if care is free for children less than five years, efforts should be increased by the government and NGOs to enhance preventive measures in order to reduce the morbidity and mortality rate in this population group.

\section{References}

1. http://www.who.int/violence_injury_prevention/road_traffic/en/

2. http ://www.who.int/violence_injury_prevention/child/en/

3. International Human Development Indicators [webpage on the Internet].United Nations Development Programme; 2011. http://hdrstats.undp.org/en/indicators/default.html

Copyright: $(2017$ Chaibou MS. This is an open-access article distributed under the terms of the Creative Commons Attribution License, which permits unrestricted use, distribution, and reproduction in any medium, provided the original author and source are credited. 